【招 待 講 演】

\title{
Positional Cloning of the shaker-1 Gene : A Myosin VII Involved in Sensory Hair Cell Development and Function
}

\author{
Steve D.M. BROWN,1) Tim SELF, ${ }^{2)}$ Mary MAHONY, ${ }^{2)}$ Jane FLEMING, ${ }^{2)}$ \\ Angela PEARCE, ${ }^{\text {) }}$ David HARVEY, ${ }^{2)}$ Jo CABLE, ${ }^{2)}$ Philomena MBURU, ${ }^{\text {) }}$ \\ James WALSH, ${ }^{1)}$ Fernando GIBSON, ${ }^{1)}$ Anabel VARELA ${ }^{1)}$ \\ and Karen P. STEEL ${ }^{2)}$ \\ 1) Department of Biochemistry and Molecular Genetics, St. Mary's Hospital \\ Medical School, London W2 1PG, UK \\ 2) MRC Institute of Hearing Research, Nottingham, NG7 2RD, UK
}

Shaker-1 homozygotes show typical neuroepithelial-type inner ear defects, causing hyperactivity, circling and head-tossing, plus progressive hearing impairment leading to early deafness. We have identified by posittional cloning the shaker-1 locus of the mouse as the gene encoding an unconventional myosin, myosin VII (Gibson et al.: Nature, 374, 62-64 (1995)). Myosin VII mRNA is present predominately in the sensory hair cells of all inner ear neuroepithelia. Of the seven mutations of shaker-1 available, we have identified three (two missense mutations and a $3^{\prime}$ splice site mutation leading to an inframe deletion) at different sites affecting the head region of the protein. The original shaker-1 mutation has the least severe effects of the seven mutations. Hair cells look ultrastructurally normal for the first few weeks after birth, and cochlear microphonics start to develop normally until about 15 days after birth suggesting that outer hair cells function normally at first. However, compound action potentials never develop normally, which indicates that the inner hair cells may be earliest cell type to be affected. The other shaker-1 mutations are all more severe in their effects on the cochlea and most show no signs of any cochlear responses at any stage of development. The early development of the stereocilia bundles is abnormal, with aberrant bundle arrangement in most hair cells from birth onwards, followed by rapid hair cell degeneration. These findings suggest that myosin VII has at least two functions in the inner ear. Firstly, it is involved with organisation of the stereocilia bundles, leading to severe dysfunction of hair cells. Secondly, it has a role in inner hair cell function, because in the original shaker-1 allele, the mutant myosin permits normal stereocilia bundle formation, but affects cochlear responses later in development. Finally, we have also shown that the human homologue of shaker-1 is the gene affected in Usher syndrome type 1b (Weil et al.: Nature, $\mathbf{3 7 4}$ 60-61 (1995)) in which progressive retinitis pigmentosa accompanies the auditory and vestibular defects. We have seen no evidence of retinitis pigmentosa in shaker-1 mutant mice up to a year old. 